\title{
Study Kidney Functions, Body Weight, Blood Pressure in Patients with Pregnancy Induced Hypertension (PIH)
}

\author{
Mohammed Kambal NH${ }^{1}$, Bani IA ${ }^{2}$ and Sabahelkhier MK $^{3}$ \\ ${ }^{1}$ Department of Clinical Nutrition, Collage of Applied Medical Sciences, Jazan \\ University, Saudi Arabia \\ ${ }^{2}$ Adjucant Professor Global Health Dept., Rollins School of public Health, Emory
}

University, USA

${ }^{3}$ Department of Biochemistry and Molecular Biology, Faculty of Science and Technology, Al-Neelain University, Sudan

*Corresponding author: Nahla Hwait alla Mohammed Kambal, AlNeelain University, Khartoum, Sudan, Tel: 0534278252; E-mail: nahlakambal85@hotmail.com

\section{Research Article \\ Volume 3 Issue 1}

Received Date: December 23, 2017

Published Date: January 19, 2018

\section{2; E-mail. nahlakambal85@hotmail.com}

\section{Abstract}

An aim of this study is to assess weight, pressure and kidney functions of healthy (control) and patient with PIH (eclampsia). Data was collected by using structured questionnaire. Body weight was measured to an accuracy of $0.1 \mathrm{~kg}$ using a standard balance scale manufactured by Microlife $\AA$, Switzerland, and clinical data was obtained from the subjects' records. The results were revealed that the greater levels of creatinine, blood urea, sodium, and potassium in PIH (eclampsia) patients compared with health group.

Keywords: Kidney; Weight; Pressure; Hypertension

Abbreviations: PIH: Pregnancy Induced Hypertension; SBP: Systolic Blood Pressure; DBP: Diastolic Blood Pressure.

\section{Introduction}

Pregnancy induced hypertension (PIH) is a hypertensive a common and dangerous disorder in pregnancy that occurs in the absence of other causes of elevated blood pressure. Pregnancy-induced hypertension is affecting both the child's and mother's morbidity and mortality [1]. PIH includes gestational hypertension as well as preeclampsia and eclampsia. Gestational hypertension is characterized by an abnormal rise in blood pressure that usually develops after the 20th week of pregnancy. In addition to hypertension, symptoms of preeclampsia include proteinuria and edema. If the condition progresses to eclampsia, life-threatening convulsions and coma can occur. PIH can also result in preterm labor and delivery and low-birth-weight infants [2]. Even in developed countries, prenatal mortality rates in infants of mothers who developed pre-eclampsia were five times more frequent than non-pre-eclamptic mothers [3]. The worldwide prevalence of pre-eclampsia is 5-10\% [4]. One study in Tehran reported the local incidence of preeclampsia to be $5 \%$. Abdelamarouf, et al. stated that PIH is a common condition in Sudanese pregnant women as observed by practicing doctors, although here is no published data of its prevalence in Sudan [5].

The objectives of this study: to assess the weight, pressure and kidney functions for patient of $\mathrm{PIH}$ (eclampsia) comparing with health women. 


\section{International Journal of Biochemistry \& Physiology}

\section{Material and Method}

\section{Material}

This cross sectional study was conducted in Khartoum State, Sudan in 2016, Study duration was extended from 2016-2017. The study was undertaken on 100 pregnant women. Thirty five pregnant women with PIH (eclampsia) admitted in three teaching hospitals Elmogran, Bashair and of maternal Hospital were randomly selected as case group. From the same health facilities, sixty five (65) healthy pregnant women without a history of hypertension were randomly selected as control group for comparison. After explaining aims and objectives, informed consent was obtained from each subject for participation in this study. Ethical approval for the study was obtained from the ethical commission of the collage of postgraduate studies in $\mathrm{Al}$ Neelain University. Data collection, demographic data and clinical data was collected by using structured questionnaire. The participants were assisted on how to fill the questionnaire. Patient's information like maternal age, parity and gestation age at screening was recorded

\section{Methods}

Body weight (Kg): It was measured to an accuracy of $0.1 \mathrm{~kg}$ using a standard balance scale manufactured by Microlife ${ }^{\circledR}$, Switzerland.

Blood pressure (mm Hg): Blood pressure of the participants were measured at the time of enrolment, by using standard methods.

Blood urea (mg $\backslash \mathbf{d l})$ : Urea kits were used to determine urea Nitrogen concentration in blood serum sample according to method of Chaney and Marbach One hundred $(\mu \mathrm{l})$ of blood serum were transferred into a test tube [6]. One milliters reagent 1(Phosphate buffer $120 \mathrm{mmol} \backslash \mathrm{l}$, sodium salicylate $60 \mathrm{mmol} \backslash \mathrm{l}$, sodium nitroproside $5 \mathrm{mmol} \backslash \mathrm{l}$, EDTA $1 \mathrm{mmol} \backslash \mathrm{l}$ and urease $5 \mathrm{KU} \backslash \mathrm{L})$ were added, mixed the solution and left to stand 5 minutes at room temperature, then one $\mathrm{ml}$ of reagent 2 (phosphate buffer $120 \mathrm{mmol} \backslash \mathrm{l}$, sodium hydroxide $4000 \mathrm{mmol} \backslash \mathrm{l}$ and sodium hypochlorite $10 \mathrm{mmol} \backslash \mathrm{l}$ ) was added and then left to stand 10 minutes before absorbance were read at $600 \mathrm{~nm}$ by using spectrophotomer (Model No. 1904 +. Serial number 1904 -5252). Blank and urea standard were read by using spectrophotometer at $600 \mathrm{~nm}$.

Blood creatinine $(\mathbf{m g} \backslash \mathbf{d l})$ : Blood serum creatinine was measured according to Fabiny and Etlingshausen [7]. One hundred microliters of blood serum were transferred into spectrophotometer cuvette. One milliters creatinine kit reagent (equal volume of reagent 1 (picric acid $8.73 \mathrm{mmol} \backslash \mathrm{l}$ ) and reagent 2 (sodium hydroxide $312.5 \mathrm{mmol} \backslash \mathrm{l}$ and disodium phosphate 12.5 mmol $\backslash \mathrm{l})$ was added and then mixed and left 10 seconds at room temperature. An absorbance was read at 500 nm by using spectrophotomer (Model No. $1904+$, Serial number 1904-5252). A blank used to calibrate spectrophotomer. Creatinine kit was used as reference standard.

Sodium and Potassium (mg $\backslash \mathrm{dl})$ : Extraction of minerals ( $\mathrm{Na}$ and $\mathrm{K}$ ) was done according to method described by Pearson [8]. Then concentration of $\mathrm{Na}$ and $\mathrm{K}$ in blood sample was measured by using atomic absorption.

\section{Statistical Analysis}

It was performed by use of SPSS versionl6 (Statistical Package for the Social Sciences).The differences between the groups were tested for significance by student's t-test, Onaway ANOVA test and chi-square test. Data were expressed as the mean $\pm \mathrm{SD}$. P-values $\leq 0.05$ are considered statistically significant.

\section{Results and Discussion}

\section{History of Health and Patient with PIH \& Eclampsia}

History of health and patient with PIH \& eclampsia was presented in Table 1 . The mean scores of age, no of pregnancies, no of living children and no of stillbirths for control group were $27.8 \pm 52.71,3.86 \pm 2.38$, $2.06 \pm 1.78$, and $1.66 \pm 2.42$ compared to $29.69 \pm 6.82$, $3.29 \pm 2.50,1.50 \pm 1.75$, and $0.61 \pm 1.48$ for $\mathrm{PIH}$ and eclampsia groups, respectively. Significant differences in mean scores of no of neonatal death and gestational (weeks) between the two groups were observed at $0.76 \pm 0.76$ and $18,94 \pm 8.46$ for the control, $0.19 \pm 0.40$ and $29.51 \pm 8.79$ for PIH and eclampsia group at $p$ value $(0.000)$ for the two variables, respectively. Significant differences in mean scores of no of neonatal death and gestational (weeks) between the two groups were observed at $p$ value $(0.000)$ for the two variables, which can be attributed to the fact that PIH is rare in early pregnancy. Gestational hypertension or pregnancyinduced hypertension (PIH) is the development of new hypertension in a pregnant woman after 20 weeks gestation without the presence of protein in the urine or other signs of preeclampsia. Earlier studies have also showed that PIH was associated with decreased risks of infant mortality, early neonatal mortality, and late neonatal mortality [9-13]. 


\section{International Journal of Biochemistry \& Physiology}

\begin{tabular}{|c|c|c|c|c|}
\hline Item & Control & PIH \& eclampsia & T-Test & P-Value \\
\hline Age (years) & $27.8 \pm 52.71$ & $29.69 \pm 6.82$ & 1.381 & 0.172 \\
\hline No of pregnancy (Para) & $3.86 \pm 2.38$ & $3.29 \pm 2.50$ & 1.115 & 0.269 \\
\hline No of living children & $2.06 \pm 1.78$ & $1.50 \pm 1.75$ & 1.433 & 0.156 \\
\hline No of still birth & $1.66 \pm 2.42$ & $0.61 \pm 1.48$ & 2.023 & 0.049 \\
\hline No of Neonatal death & $0.76 \pm 0.76$ & $0.19 \pm 0.40$ & 3.972 & 0 \\
\hline Gestational(Weeks) & $18.94 \pm 8.46$ & $29.51 \pm 8.79$ & 5.815 & 0 \\
\hline
\end{tabular}

Table 1: History of healthy (control) and PIH \& eclampsia groups

\section{Body Weight and Blood Pressure}

Body weight and Blood pressure measures were presented in Table 2. Pre-pregnancy weight and current weight for control and PIH (eclampsia) groups were $68.38 \pm 10.66$ and $72.42 \pm 12.33$, respectively. Systolic blood pressure and diastolic blood pressure for control group were $115.77 \pm 7.81$ and $37.47 \pm 5.73$, while $\mathrm{PIH}$ (eclampsia) group recorded $154.91 \pm 18.61$ and $100.69 \pm 13.22$, respectively. These results indicate that systolic blood pressure (SBP) and diastolic blood pressure (DBP) in PIH (eclampsia) patients were significantly higher than those values of control subjects. The results showed significantly increased levels of SBP and DBP ( $p=0.000)$ in PIH (eclampsia) patients. According to American College of Obstetricians and Gynecologists, preeclampsia is defined as the two categories (1) Systolic blood pressure (SBP) greater than or equal to $140 \mathrm{~mm} \mathrm{Hg}$ or a diastolic blood pressure (DBP) greater than or equal to $90 \mathrm{~mm} \mathrm{Hg}$ or higher, on two occasions at least 4 hours apart in a previously normotensive patient, or (2) Systolic blood pressure (SBP) greater than or equal to $160 \mathrm{~mm} \mathrm{Hg}$ or a DBP greater than or equal to $110 \mathrm{~mm} \mathrm{Hg}$ or higher (In this case, hypertension can be confirmed within minutes to facilitate timely antihypertensive therapy) [14].

\begin{tabular}{|c|c|c|c|c|}
\hline Item & Control & PIH \& eclampsia & T-Test & P-Value \\
\hline Pre pregnancy weight $(\mathrm{Kg})$ & $68.38 \pm 10.66$ & $72.42 \pm 12.33$ & 1.048 & 0.311 \\
\hline Current weight (Kg) & $70.25 \pm 12.35$ & $74.11 \pm 14.16$ & 1.361 & 0.178 \\
\hline Systolic blood pressure( $\mathrm{mm} \mathrm{Hg})$ & $115.77 \pm 7,81$ & $154.91 \pm 18,61$ & 11.89 & 0 \\
\hline Diastolic blood pressure (mm Hg) & $37.47 \pm 5.73$ & $100.69 \pm 13.22$ & 10.898 & 0 \\
\hline
\end{tabular}

Table 2: Weight and pressure of healthy (control) and PIH \& eclampsia

\section{Blood Creatinine and Urea}

Table 3 indicated that the kidney function of healthy (control) and PIH (eclampsia) groups. PIH \&eclampsia group scored significantly higher means ( $p$ value $<0.05$ ) compared to control group at mean scores $36.54 \pm 10.44$ and $19.26 \pm 8.17$ for blood urea, $1.42 \pm 0.25$ and $1.08 \pm 1.27$ for creatinine, $141.66 \pm 3.89$ and $138.73 \pm 3.52$ for sodium, $5.37 \pm 1.06$ and $4.15 \pm 0,49$ for potassium, respectively.

\section{Conclusion}

The results indicated that significant differences in no of neonatal death and gestational (weeks) between the two groups (Control and pregnancy-induced hypertension). Pregnancy-induced hypertension (PIH) is rare in early pregnancy. Gestational hypertension or pregnancy-induced hypertension (PIH) is the development of new hypertension in a pregnant woman after 20 weeks gestation without the presence of protein in the urine or other signs of preeclampsia. Systolic blood pressure (SBP) and diastolic blood pressure (DBP) in PIH (eclampsia) patients were significantly higher than those values of control subjects. PIH \& eclampsia group had significantly higher values compared to control for creatinine, sodium and potassium.

\begin{tabular}{|c|c|c|c|c|}
\hline Kidney function & Control & PIH\&eclampsia & T-Test & P-Value \\
\hline Blood urea mg/dL & $19.26 \pm 8.17$ & $36.54 \pm 10.44$ & 8.488 & 0 \\
\hline Creatinine mg/dL & $1.08 \pm 1.27$ & $1.42 \pm 0.25$ & 2.042 & 0.045 \\
\hline Sodium mg/dL & $138.73 \pm 3.52$ & $141.66 \pm 3.89$ & 3.718 & 0 \\
\hline Potassium mg/dL & $4.15 \pm 0,49$ & $5.37 \pm 1.06$ & 6.47 & 0 \\
\hline
\end{tabular}

Table3: Kidney function of healthy (control) and PIH \& eclampsia 


\section{International Journal of Biochemistry \& Physiology}

\section{References}

1. Kazemian E, Dorosty-Motlagh AR, Sotoudeh G, Eshraghian MR, Ansary S, et al. (2013) Nutritional status of women with gestational hypertension compared with normal pregnant women. Hypertens Pregnancy 32(2): 146-156.

2. Ritchie LD, King JC (2000) Dietary calcium and pregnancy-induced hypertension: is there a relation? Am J Clin Nutr 71(5): 1371S-1374S.

3. Roberts JM, Balk JL, Bodnar LM, Belizán JM, Bergel E, et al. (2003) Nutrient involvement in preeclampsia. J Nut 133(5): 1684S-1692S.

4. Olafsdottir AS, Skuladottir GV, Thorsdottir I (2006) Relationship between high consumption of marine fatty acids in early pregnancy and hypertensive disorders in pregnancy. BJOG 113(3): 301-309.

5. Abdelmarouf HM, Asma AD, Yousif HM, Osman HM, Idris A (2007) Serum calcium level as a marker of pregnancy-induced hypertension. Sudan JMS 2(4): $1-4$.

6. Chaney AL, Marbach EP (1962) Modified reagent for determination urea and ammonia. Clin Chem 8: 130-132.

7. Fabiny dl, Ertingshausen G (1971) Automated reaction rate method for determination serum creatinine with centrifugation. Clin Chem 17(8): 696-700.

8. Pearson D (1970) The chemical analysis of foods: J and A Churchill. 104 Gloucester places- London.
Nutritional value and fatty acid composition $\mathrm{o}$ /some high yielding varieties of bajara. Bull of Grain Tech (21): 41.

9. Cunningham FG, Leveno KJ, Bloom SL, Spong CY, Dashe JS, et al. (2014) 24th (Edn.), New York: McGraw-Hill Education.

10. Chen XK, Wen SW, Smith G, Yang Q, Walker M (2007) Pregnancy-induced hypertension and infant mortality: Roles of birthweight centiles and gestational age. BJOG 114(1): 24-31.

11. Chen XK, Wen SW, Smith G, Yang Q, Walker M (2006) Pregnancy-induced hypertension is associated with lower infant mortality in preterm singletons. BJOG 113(5): 544-551.

12. Von Dadelszen P, Magee LA, Taylor EL, Muir JC, Stewart SD, et al. (2005) Maternal hypertension and neonatal outcome among small for gestational age infants. Obstet Gynecol 106(2): 335-339.

13. Regev RH, Lusky A, Dolfin T, Litmanovitz I, Arnon S, et al. (2003) Excess mortality and morbidity among small-for-gestational-age preterm infants: a population-based study. J Pediatr 143(2): 186-191.

14. American College of Obstetricians and Gynecologists, Task Force on Hypertension in Pregnancy (2013) Hypertension in pregnancy. Report of the American College of Obstetricians and Gynecologists' Task Force on Hypertension in Pregnancy. Obstet Gynecol 122(5): 1122-1131. 